\title{
Síndrome hemolítico urémico asociado a infección intestinal por Escherichia coli productora de shigatoxina (STEC) en pacientes chilenos: aspectos clínicos y epidemiológicos
}

\author{
Valeria Prado J., Felipe Cavagnaro S.M. y Grupo de Estudio de Infecciones por STEC
}

\section{Hemolytic uremic syndrome associated to shigatoxin producing Escherichia coli in Chilean children: Clinical and epidemiological aspects}

Clinical and epidemiological aspects of shigatoxin producing E. coli (STEC) infections and hemolytic uremic syndrome (HUS) are reviewed. Surveillance results from 14 sentinel centers during 2000-2002 showed a mean incidence rate of 3.4 HUS cases per 100.000 children, with the highest incidence in the 6 to 28 month age group. Disease is endemic with summer peaks. Between 1988 and 2002 we obtained the clinical characteristics of a group of 119 HUS children with the following results: mean age 16 months, bloody diarrhea $57.8 \%$, no previous diarrhea 9\%, 60\% received antibiotics, $72 \%$ had oligoanuria, 53\% required dialysis, $15 \%$ had seizures and $31 \%$ had dizziness; mortality was $3 \%$. Four foodborne outbreaks have been detected in Santiago, two outbreaks occurred in household settings, one in a Day Care Center and one in a Neonatal Unit. Recommendations for diagnosis, treatment and prevention of STEC infections, including potential vaccines are discussed.

Key words: Shigatoxin producing E.coli, hemolytic uremic syndrome, treatment, prevention.

Palabras clave: Escherichia coli productora de shigatoxina, (STEC), síndrome hemolítico urémico, epidemiología, tratamiento, prevención.
Grupo de Estudio de Infecciones por STEC: Jaime Cordero T., Hospital L. Calvo Mackenna y Clínica Las Condes; Juan P. Díaz G., Hospital Exequiel González Cortés; Rosanna Lagos Z., Centro para Vacunas en Desarrollo; Jean Grandy H., Hospital de Arica; Sandra Moraga V., Hospital de Coquimbo; Carlos Flores B., Hospital de Ovalle; Gustavo Ríos R., Hospital Gustavo Fricke de Viña del Mar; Carmen L. Avilés L.y M. Cristina Casado F.,Hospital San Borja Arriarán; Jaime Rodríguez T., Hospital Roberto Del Río; Priscilla Prado D., Hospital Padre Hurtado; Heidy Leiva H., Hospital de Rancagua; Richard Ríos R., Hospital de Valdivia; Alexis Strickler P., Hospital de Puerto Montt; Hernán Villalón U.y M. Amelia Espinoza B., Hospital de Coyhaique, Claudia Durán T. y Roberto Vidal A. ICBM, Facultad de Medicina, Universidad de Chile

(Nota. Las filiaciones de los pediatras corresponden al período 2000-2002 y pueden haber cambiado).

\section{Introducción}

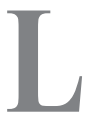

as infecciones por Escherichia coli productora de shigatoxina (Shigatoxin-producing Esche richia coli-STEC, en inglés) han sido identificadas como un importante problema de salud pública en países desarrollados, donde causan brotes de infecciones alimentarias y de síndrome hemolítico urémico $(\mathrm{SHU})^{1,2}$. Dentro de Latinoamérica, el problema parece concentrarse en países del Cono Sur Argentina y Chile- donde existen registros de casos esporádicos de SHU durante todo el año, aunque no se han notificado brotes importantes de gastroenteritis, tal vez por la falta de adecuados programas de vigilan$\operatorname{cia}^{3,4}$.

El objetivo de este artículo es revisar el tema, aportar información sobre la situación epidemiológica de las infecciones por STEC en Chile (datos inéditos de estudios realizados por los autores) y analizar estrategias para el manejo y control adecuados.

El SHU es la complicación más seria de las infecciones por STEC y, por su gravedad clínica, es la parte visible del problema. El riesgo de desarrollar un SHU en un paciente que se infecta con STEC depende de complejas interacciones entre el agente y el hospedero, y uno de los factores que influyen en forma importante es el serogrupo o serotipo de STEC. En situaciones de brotes, se ha observado que cuando el agente infectante es un STEC del serotipo O157: H7, el riesgo puede alcanzar a $10-15 \%$; en cambio, si el serotipo pertenece al grupo de los no- O157, la probabilidad de la desarrollar un SHU disminuye a $2 \% 5$.

El SHU es una entidad nosológica de la familia de las microangiopatías trombóticas, caracterizada por
Universidad de Chile

Facultad de Medicina

Instituto de Ciencias BiomédicasICBM

Programa de Microbiología y Micología (VPJ)

Pontificia Universidad Católica de Chile

Facultad de Medicina

Departamento de Pediatría (FCSM)

Financiamiento: Proyecto Fondecyt 1000636.

Artículo por invitación Recibido: 3 junio 2008

Correspondencia a: Valeria Prado Jiménez vprado@med.uchile.cl 
anemia hemolítica microangiopática, trombocitopenia y compromiso renal agudo de diversa magnitud. Fue descrito por primera vez en 1955 por Gasser y cols ${ }^{6}$, y debieron transcurrir casi 30 años hasta que Karmali y cols, demostraron la asociación entre este síndrome y la diarrea causada por bacterias productoras de citotoxinas, las cuales se relacionan desde el punto de vista biológico e inmunogénico con la toxina Shiga ${ }^{7}$. Estas citotoxinas, toxinas tipo Shiga o shigatoxinas (Stx), también se denominan verotoxinas, por el efecto citopático característico que producen en cultivo de células Vero. Se han descrito dos tipos de Stx: tipo 1 (Stx1) y 2 (Stx2), las cuales tienen una actividad biológica similar, aunque difieren entre sí desde el punto de vista antigénico ${ }^{8}$.

El SHU constituye una de las principales causas de insuficiencia renal aguda en la población pediátrica a nivel mundial, se asocia a una significativa co-morbilidad y es una causa frecuente de daño renal cróni$\mathrm{co}^{9}$. Su impacto mediático ha contribuido a mejorar las normas de higiene asociadas al manejo de productos animales, los cuidados necesarios de estos alimentos para el consumo humano y también al desarrollo de interesantes líneas de investigación basadas en el mejor entendimiento de su etiopatogenia. Este último se ha traducido en el estudio de alternativas preventivas de la enfermedad, como lo son moléculas bloqueadoras de las toxinas Stxs y anticuerpos neutralizantes.

Clásicamente se ha dividido al SHU entre aquellos asociados a un pródromo de diarrea (SHU D+, 90\%) y aquellos sin este antecedente (SHU D-, 10\%), aunque

\begin{tabular}{|c|c|c|c|}
\hline Centro & Población bajo 15 años de edad & Casos de SHU* & Tasa por $10^{5}$ \\
\hline Arica & 54.000 & 0,3 & 0,5 \\
\hline Ovalle & 30.500 & 1,5 & 4,9 \\
\hline Coquimbo & 44.700 & 1,3 & 2,9 \\
\hline Viña del Mar & 90.000 & 4,0 & 4,4 \\
\hline SSM Oriente & 266.000 & 8,0 & 3,0 \\
\hline SSM Central & 209.000 & 2,3 & 1,1 \\
\hline SSM Sur & 304.000 & 6,6 & 2,2 \\
\hline SSM Norte & 231.000 & 2,0 & 0,8 \\
\hline SSM Occidente & 97.000 & 4,5 & 4,6 \\
\hline Rancagua & 61.300 & 5,5 & 9,0 \\
\hline Valdivia & 36.400 & 1,3 & 3,6 \\
\hline Puerto Montt & 46.300 & 1,3 & 2,8 \\
\hline Coyhaique & 14.800 & 0,7 & 4,7 \\
\hline Promedio & - & - & 3,4 \\
\hline
\end{tabular}

quizás sería más correcto diferenciar aquellos cuadros de SHU con evidencias de infección por STEC o sin ella, ya que existen cuadros D- con Stx + en deposiciones ${ }^{9}$. Debido a que la etiopatogenia y pronóstico de ambos es muy diferente, la presente revisión se centrará en el primer grupo (SHU D+), el de mayor prevalencia y de implicancias epidemiológicas más importantes.

Como hemos mostrado en estudios previos, en Chile más de $90 \%$ de los casos de SHU se asocian a infección por STEC, lo cual fue posible documentar utilizando en forma complementaria diferentes técnicas microbiológicas como el aislamiento de STEC en deposiciones, detección de Stx en deposiciones y estudio de anticuerpos anti-Stx ${ }^{10}$. El aislamiento de la bacteria en deposiciones sólo se logra en la mitad de los pacientes, ya que el SHU se presenta en promedio luego de 8 a 10 días de iniciado el cuadro de diarrea y en esa etapa, en muchas ocasiones ya no está presente la STEC porque ha sido eliminada por el sistema inmune, o por el uso de antimicrobianos en la etapa de diarrea $^{10}$.

\section{Epidemiología}

Incidencia de síndrome hemolítico urémico en Chile. En nuestro país, el SHU es de notificación obligatoria. Un estudio retrospectivo que realizamos en la Región Metropolitana (RM) entre 1992 y 1994, reveló una incidencia anual de SHU de 3,2 casos por 100.000 niños bajo 5 años de edad ${ }^{11}$.

Posteriormente, a partir de enero del año 2000 y por un período de tres años, se planificó un estudio prospectivo con la participación de una red de 14 centros centinelas a lo largo del país, incluyendo hospitales importantes en el norte (Arica, Ovalle, Coquimbo, Viña del Mar), en el centro (seis hospitales en Santiago, uno en Rancagua) y en el sur (Valdivia, Puerto Montt, Coyhaique). Pediatras centinelas en cada hospital participante registraban semanalmente la ocurrencia o no ocurrencia de casos de SHU, utilizando una definición estandarizada de caso.

Durante el año 2000 participaron 11 hospitales, y se notificaron 33 casos de SHU; en el año 2001 aumentó a 14 el número de hospitales de la red, los cuales notificaron 45 casos y estos 14 centros registraron un total de 40 casos en el año 2002. Considerando como denominador la población asignada por el Ministerio de Salud a cada hospital, se calcularon las tasas de incidencia para cada centro, las cuales variaron entre 0,5 y 9,0 casos por 100.000 niños bajo 15 años de edad. No están disponibles las cifras de niños bajo 5 años (Tabla 1). Se registraron casos durante todos los meses 
Tabla 2. Distribución por edad de 119 casos de síndrome hemolítico urémico notificados en período de vigilancia. Chile, 2000-2002

\begin{tabular}{|lccc|}
\hline Edad & $\mathbf{2 0 0 0}$ & $\begin{array}{c}\text { No de casos } \\
\mathbf{2 0 0 1}\end{array}$ & $\mathbf{2 0 0 2}$ \\
$<6$ meses & 0 & 0 & 0 \\
$6-12$ meses & 5 & 6 & 7 \\
$13-24$ meses & 11 & 20 & 13 \\
$25-28$ meses & 9 & 13 & 8 \\
$>48$ meses & 8 & 6 & 12 \\
\hline Total & 33 & 45 & 40 \\
\hline
\end{tabular}

del año, con una incidencia estacional mayor en los meses calurosos; el número de casos entre los meses de octubre y marzo fue superior al número registrado entre abril y septiembre $(\mathrm{p}<0,01)$. No se observaron diferencias significativas en la distribución estacional de los casos de SHU (Figura 1). En este período, 78\% de los casos de SHU ocurrió en niños entre 6 y 48 meses, la edad promedio fue de 27,5 meses (rango 6-84 meses) (Tabla 2). La letalidad registrada, en esta serie de casos de la vigilancia en los 14 centros centinelas, fue de $2,7 \%$.

$\mathrm{Si}$ consideramos que los casos de SHU representan sólo $10 \%$ de las infecciones intestinales por STEC, se puede obtener una aproximación de la magnitud de la circulación de este patógeno en nuestro medio. Sin embargo, en el ámbito clínico, esta dimensión se desconoce porque muy pocos laboratorios en el país incluyen la búsqueda de STEC en el estudio de un coprocultivo y, los que lo hacen, sólo enfocan el estudio al STEC O157, el cual es más fácil de identificar por la característica de no fermentar el sorbitol. Muy po$\cos$ laboratorios tienen la capacidad para identificar los STEC no-O157, pues se requiere la detección de los factores o genes de virulencia que caracterizan a los STEC.

Estos estudios de vigilancia han mostrado que las infecciones por STEC y el SHU constituyen un problema endémico en Chile, con casos durante todo el año y en todo el territorio, aunque se observan diferencias en las tasas, con algunas zonas de mayor incidencia como Rancagua (Región del Libertador B. O'Higgins), donde sería necesario investigar la existencia de factores de riesgo.

\section{Manifestaciones clínicas}

Características clínicas de pacientes con síndrome hemolítico urémico en Chile. Durante el período

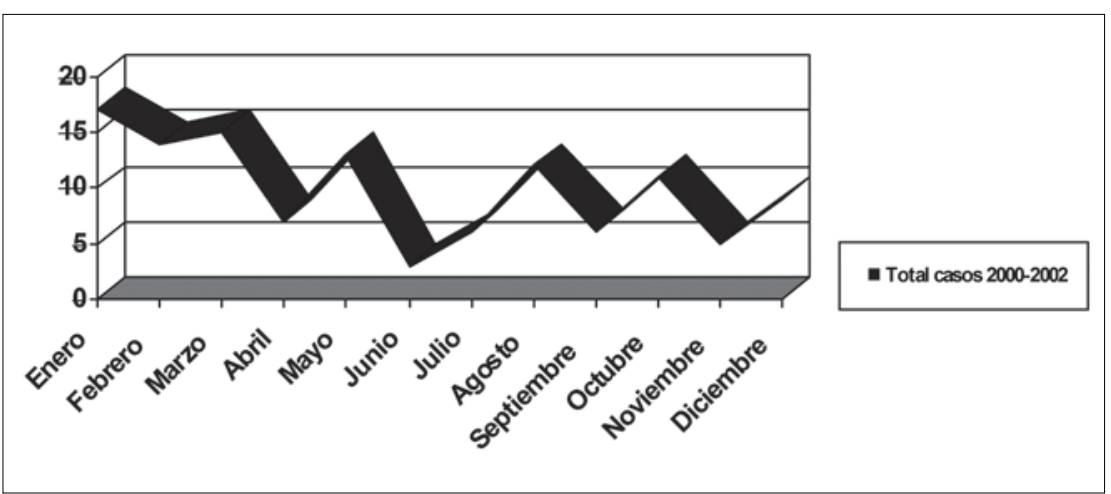

Figura 1. Distribución estacional de los 118 casos de SHU. Período 2000-2002.

Tabla 3. Características clínicas de 119 pacientes con diagnóstico de síndrome hemolítico urémico hospitalizados en la Región Metropolitana, Chile. Período 1988-2002

\begin{tabular}{|lr|}
\hline Edad (mediana) & 16 meses \\
\hline Sexo masculino & $63 \%$ \\
\hline Pródromo de diarrea & $91 \%$ \\
\hline Duración de diarrea (mediana) & 6 días \\
\hline Intervalo: Cese de diarrea - SHU (mediana) & 1 día \\
\hline Uso previo de antimicrobianos & $60 \%$ \\
\hline Alteración de la diuresis & $72 \%$ \\
\hline
\end{tabular}

1988-2002, con la participación activa de profesionales del "Grupo de estudio de infecciones por STEC" de diferentes servicios pediátricos de la RM, se elaboró una ficha médica consensuada para registrar datos clínicos y de laboratorio en pacientes con el diagnóstico de SHU. Se definió caso de SHU como: un paciente con anemia hemolítica (hematocrito $\leq 30 \%$ y observación de esquistocitos), insuficiencia renal aguda (creatininemia $>1 \mathrm{mg} / \mathrm{dl}$ ) y trombocitopenia, (recuento de plaquetas $<150.000 / \mathrm{mm}^{3}$ ). Se registraron los siguientes datos: edad, sexo, días de hospitalización, pródromo de diarrea, características y duración de la diarrea, intervalo entre el cese de la diarrea e ingreso, uso de antibacterianos previos, dosis empleadas, alteración de la diuresis y su duración, compromiso de conciencia, convulsiones, hipertensión arterial, presencia de esquistocitos, hematocrito mínimo, creatininemia máxima, recuento leucocitario máximo, VHS, PCR, sobrevida y secuelas.

En todos los pacientes se tomó una muestra de deposición al ingreso al hospital para cultivo y detección de E. coli productora de Stx, utilizando técnicas moleculares implementadas en el Laboratorio de Enteropatógenos del Programa de Microbiología de la 
Facultad de Medicina de la Universidad de Chile $^{12}$.

En este período se acumuló una serie de 119 niños con diagnóstico de SHU. Las características generales de la población al momento del ingreso al hospital se muestran en la Tabla 3. No se observó diferencias en la distribución por sexo, $96,6 \%$ de los casos se presentó en niños bajo 5 años de edad, con un rango entre 2 meses y 7 años. El pródromo de diarrea estaba presente en $91 \%$ de los pacientes, siendo disentérica en $57,8 \%$ de ellos. El 53\% de los pacientes ingresó al hospital con diarrea y el máximo intervalo entre el término de la diarrea e internación fue de 10 días. Un $72 \%$ de los pacientes ingresó con alteración de la diuresis cursando con oligoanuria, en una mediana de dos días. En el grupo de pacientes que recibió antimicrobianos previos al diagnóstico de SHU, 43\% recibió cloranfenicol, 22,5\% cotrimoxazol, 14\% furazolidona, $14 \% \beta$-lactámicos, $8 \%$ cefalosporinas o ciprofloxacina.

En la Tabla 4 se muestran los valores de los parámetros de laboratorio observados en esta serie de pacientes con SHU, considerando variables de reacción inflamatoria, anemia y función renal. El 77\% presenta una creatininemia máxima sobre $1,5 \mathrm{mg} / \mathrm{dl}, 72,1 \%$ un recuento de plaquetas inferior a $100.000 / \mathrm{mm}^{3}$ y $71 \%$ de los pacientes en que se realizó PCR, el valor fue superior a $10 \mathrm{mg} / \mathrm{dl}$.

Durante la hospitalización, 31\% presentó compromiso neurológico, con una duración promedio de 4 días; la mediana de crisis convulsivas fue de dos episodios. El resto de características registradas se muestra en la Tabla 5.

Un $21 \%$ de los pacientes de esta serie presentó secuelas al momento del alta (Tabla 5), siendo las más frecuentes hipertensión arterial (n: 12), insuficiencia renal (n: 10), anemia (n: 4) y cuatro pacientes con alteraciones neurológicas (un paciente con infarto cerebral, dos pacientes con atrofia cerebral y un paciente

Tabla 4. Parámetros de laboratorio en 119 pacientes con síndrome hemolítico urémico hospitalizados en la Región Metropolitana, Chile. Período 1988-2002

\begin{tabular}{|lr|}
\hline Parámetro & Valor \\
\hline Esquistocitos & $95 \%$ \\
PCR mg/dl (mediana) & 23 \\
VHS mm/h (mediana) & 30 \\
Hematocrito mínimo, \% (mediana) & 19 \\
Creatininemia máxima, mg/dl (mediana) & 3,19 \\
Recuento leucocitario máximo /mm³ (mediana) & 15.500 \\
Plaquetas /mm³ (mediana) & 54.000 \\
\hline
\end{tabular}

con epilepsia).

Aislamiento de STEC en deposiciones. En este grupo de pacientes se obtuvo aislamiento de STEC en 46 niños $(38,6 \%)$, en 23 pacientes los STEC correspondieron al serogrupo $\mathrm{O} 157 \mathrm{y}$ en los restantes 23 el serogrupo fue no-O157.

Este estudio descriptivo permitió, en su momento, conocer las características clínicas de los pacientes con SHU en la RM y establecer comparaciones con otros países. El análisis mostró similitudes con lo descrito en otras latitudes, pero resultó interesante observar que, si bien el pródromo de diarrea estuvo presente en la mayoría de los pacientes, no se observó un período de ventana y la tríada del SHU apareció durante el curso de la diarrea. En relación a estudios epidemiológicos internacionales, la edad promedio de presentación en Santiago es menor, 16 meses contra 3,8 años en Minnessota ${ }^{13}$ y 2,75 años en Canadá ${ }^{2}$. La edad de la aparición de SHU en niños chilenos también es inferior a lo observado en Argentina, donde el promedio es de 29 meses, con un amplio rango de variación, $\pm 26,3$ meses $^{14}$. Hay coincidencias respecto a que la mayoría de los casos se presentan bajo 5 años de edad y no hay diferencias entre sexo. Los datos de la vigilancia nacional realizada entre 2000 y 2002 mostraron un promedio de edad mayor (27,5 meses), más cercano a la realidad de países industrializados. Por otra parte, destaca el alto porcentaje de niños tratados previamente con antimicrobianos en Chile, en comparación con otros países ${ }^{13}$

En cuanto a la evolución, esta serie de pacientes presenta similitudes con lo descrito en países desarrollados, con respecto al requerimiento de diálisis, cifras de complicaciones y letalidad ${ }^{2,9,13}$.

Los hallazgos observados en esta serie de casos coinciden con lo descrito por Zambrano P y col, en una serie más amplia de 354 pacientes con SHU que ingre-
Tabla 5. Hallazgos en la evolución intrahospitalaria en 119 pacientes con síndrome hemolítico urémico hospitalizados en la Región Metropolitana, Chile. Período 1988-2002

Hallazgo clínico $\quad \%$

Compromiso de conciencia 31

Convulsiones 15

Hipertensión arterial 45

Requerimiento de diálisis 53

Duración de diálisis (mediana) 9 días

Necesidad de diuréticos $\quad 57$

Letalidad 3

$\begin{array}{ll}\text { Secuelas al egreso } & 21\end{array}$ 
Posteriormente, en el año 2006 se identificó un brote de diarrea intrahospitalaria por STEC del serogrupo O6 en un servicio de recién nacidos en Santiago, que afectó a 17 neonatos, ninguno de los cuales desarrolló SHU $^{18}$

Esta vigilancia de laboratorio permitió demostrar que en Chile se registran brotes de STEC, que es posible detectar si se dispone de los recursos adecuados, y que es necesario enfatizar las medidas de seguridad en la fabricación, manipulación y consumo de alimentos.

\section{Reservorios y mecanismos de transmisión}

Las infecciones por STEC son zoonóticas, ya que las STEC forman parte de la microbiota intestinal normal de un amplio grupo de animales. El reservorio más importante para las infecciones humanas son los bovinos y porcinos. Estudios realizados en los mataderos de Santiago mostraron que $28,7 \%$ de los bovinos estudiados y $68,3 \%$ de los cerdos analizados estaban colonizados por STEC de variados serogrupos, entre ellos $\mathrm{O} 157^{19}$.

El consumo de alimentos cárneos mal cocidos derivados de los reservorios animales, puede causar infecciones en sujetos susceptibles. Además, fecas de estos animales pueden contaminar cursos de aguas superficiales, praderas y hortalizas.

En suma, los mecanismos de transmisión pueden ser muy variados e incluyen desde el consumo de hamburguesas, jugos naturales, verduras frescas y embutidos hasta el contacto con animales en granjas, bañarse en lagos o ríos y realizar picnic en el campo. Un mecanismo de transmisión importante en niños pequeños y lactantes es la contaminación cruzada de alimentos en la cocina del hogar y el contacto persona a persona ${ }^{20}$.

Factores de virulencia de Escherichia coli productora de shigatoxina y patogenia de la infección

El daño producido por las STEC está determinado fundamentalmente por la acción de las citotoxinas; sin embargo, este microorganismo posee otros mecanismos de virulencia adicionales que contribuyen a su patogenicidad.

Un factor importante es la capacidad de adherirse en forma específica y estrecha al enterocito del intestino grueso. Esta adherencia está mediada por la expresión de una proteína denominada intimina, codificada por el gen eae, el cual está ubicado en una isla de patogenicidad junto a otros genes que facilitan la colonización. Este conjunto de genes permite la expresión de proteínas que forman una especie de jeringa que entra en contacto con la membrana celular del enterocito. A través de esta jeringa, la bacteria intro- 
duce una proteína Tir (también codificada en esta isla) que se fosforila en el citoplasma del enterocito y luego se ubica en la membrana constituyéndose en el receptor de la proteína intimina. Se trata de una bacteria que forma su propio receptor y lo inocula en la célula blanco. Esta estrecha unión de la bacteria con el enterocito estimula una serie de transducción de señales que se traducen en una reorganización del citoesqueleto de la célula del epitelio intestinal, lo que se expresa con la formación de un pedestal que "acoge" a la bacteria ${ }^{8}$.

Una vez que la STEC logra colonizar el intestino, secreta las Stxs, las cuales tienen la estructura de una holotoxina, con una subunidad central A de $32 \mathrm{kDa}$ y cinco unidades periféricas B. A través de la subunidad $\mathrm{B}$, se establece la unión de la Stx con el receptor glicolípido Gb3 presente en la superficie epitelial; esto permite la entrada de la subunidad A al citoplasma celular mediante endocitosis, subunidad que finalmente interfiere con la función ribosomal, provocando una alteración letal en la síntesis de proteínas y muerte de las células blanco por apoptosis ${ }^{8}$.

En etapas sucesivas, la Stx es traslocada al torrente sanguíneo y transportada por los neutrófilos a los diferentes tejidos donde existen receptores Gb3: enterocitos, células endoteliales del glomérulo renal, membrana celular de los eritrocitos y células cerebrales, entre otras. Es así como el daño fisiopatológico que se observa en el SHU está dado fundamentalmente por la acción de las Stxs ${ }^{21}$.

Serogrupos y serotipos de Escherichia coli productora de shigatoxina. Los factores de virulencia que caracterizan a STEC se encuentran presentes en más de 70 serotipos O:H. El prototipo de las STEC y la que tiene mayor impacto clínico es, sin duda, el serotipo O157:H7; sin embargo, otros serotipos no-O157 pueden también provocar infección intestinal y SHU, entre ellos O26:H11, O55:H7, O55:H10, O111:H8 y O111:H30 .

Por lo tanto, para tener la información completa de la carga de enfermedad por STEC, es importante considerar el grupo de los no-O157 en el diagnóstico microbiológico.

\section{Diagnóstico microbiológico}

La dimensión real de la infección por STEC está subestimada en forma importante debido a las limitaciones de los laboratorios para establecer el diagnóstico. Muy pocos laboratorios, incluso en países desarrollados, buscan de rutina STEC.

La detección de STEC del serogrupo O157 es más accesible para los laboratorios clínicos, ya que la gran mayoría de las cepas 0157 son incapaces de fermentar el sorbitol. Por esto, es posible aislar la bacteria a partir de la siembra de muestras de deposición en medios selectivos que contienen este azúcar, como el agar MacConkey sorbitol. Las colonias sorbitol negativas son sospechosas de ser $\mathrm{O} 157$ y esto debe ser comprobado aglutinando estas colonias con antisueros comerciales anti O157. El aislado de una E. coli O157 en una muestra de deposición demora $48 \mathrm{hrs}$ y no confirma que estemos en presencia de una STEC, ya que es necesario demostrar que esta cepa es productora de Stxs. En nuestra experiencia hemos constatado, tanto en pacientes como en reservorios animales, la excreción de algunas cepas O157 no productoras de Stxs.

Hemos comentado anteriormente que si bien $\mathrm{O} 157$ tiene un gran impacto epidemiológico, no es posible ignorar la participación de los serogrupos no-O157 en diarrea o en SHU, si se quiere tener un diagnóstico completo del problema.

La identificación de las STEC de los serogrupos noO157 es más compleja, ya que requiere detectar presencia de los factores de virulencia que caracterizan a la STEC: la proteína intimina o su gen eae, y las toxinas Stx1 y Stx2 o sus genes (stx1, stx2). Una técnica altamente sensible y específica es la amplificación de estos genes mediante RPC. Nuestro laboratorio ha estandarizado una técnica de RPC múltiple a partir de un cultivo en agar MacConkey (colonias) que demora 48 $\mathrm{hrs}^{12}$. La RPC indica presencia de una STEC y luego es necesaria la serotipificación para identificar el serogrupo o serotipo.

Desde el punto de vista clínico es importante contar con una técnica de diagnóstico rápido y lo más práctico es la detección de Stxs en deposiciones como indicador de la presencia de cualquier serogrupo de STEC. Una técnica ampliamente utilizada es una ELISA disponible comercialmente (Premier EHEC, Meridian) que se puede realizar directamente de la muestra de deposición o a partir de colonias. En nuestra experiencia se obtienen resultados más confiables trabajando con colonias, lo que aumenta el tiempo de obtención de resultados a $24 \mathrm{hrs}^{10}$.

Recientemente está disponible una técnica rápida basada en un inmunoensayo óptico que permite detectar Stxs directamente en deposiciones (Biostar OIA SHIGATOX, Inverness). El resultado se obtiene en 1520 minutos y ha demostrado una muy buena sensibilidad y especificidad, y buena correlación con la técnica bien establecida de Premier EHEC ${ }^{22}$. Las técnicas que detectan Stxs en deposiciones son útiles como tamizaje y es necesario hacer los esfuerzos posteriores para aislar e identificar las colonias de STEC e idealmente realizar la serotipificación. 
Evolución clínica de la infección por Escherichia coli productora de shigatoxin

La dosis infectante de STEC puede ser tan baja como 50 organismos. El período de incubación generalmente es de 3 a 4 días. El cuadro gastrointestinal se inicia con diarrea acuosa; en algunos pacientes y dependiendo de las características de la cepa, al tercer o cuarto día aparecen deposiciones con sangre, que puede ser en escasa cantidad o bien una colitis hemorrágica con deposiciones líquidas con aspecto de "agua de lavado de carne". En el día $6^{\circ}-7^{\circ}$ u $8^{\circ}$ de la evolución del cuadro, pueden aparecer los síntomas y signos de SHU (Figura 2).

Si se analizan las series de pacientes chilenos con SHU, entre 60 y $80 \%$ de ellos tienen antecedente de diarrea con sangre ${ }^{23}$.

La infección cursa con fiebre moderada o sin fiebre. Es frecuente la presencia de dolor abdominal de tipo cólico, en ocasiones muy intenso. En la observación directa de las deposiciones llama la atención una escasa cantidad de leucocitos.

Aproximadamente una semana después su inicio, la diarrea disminuye y los síntomas gastrointestinales se calman. En este momento pueden aparecer evidencias de laboratorio de SHU, siendo la disminución del número de plaquetas el parámetro más precozmente alterado. Alrededor de $10 \%$ de estos pacientes desarrollará el cuadro clásico de SHU y un porcentaje similar presentará una variedad incompleta, es decir, sólo tendrá dos de los tres criterios definitorios de la enfermedad. En algunos casos, los pacientes pueden acudir por primera vez a la consulta médica con signos evidentes de un SHU avanzado, con insuficiencia renal aguda oligúrica, palidez marcada por anemia hemolítica importante y tendencia hemorragípara por la trombocitopenia. Algunos pacientes pueden debutar con síntomas neurológicos (convulsiones, coma) o complicaciones digestivas como pancreatitis, prolapso rectal o invaginación intestinal. Es frecuente la hipertensión arterial y traduce sobrecarga de volumen intravascular, así como activación del sistema renina-angiotensinaaldosterona por isquemia renal $1^{9,23,24}$. Aquellos pacientes que no presentan evidencias de laboratorio de SHU luego de tres días de resuelta la diarrea, es poco probable que desarrollen la enfermedad.

Un número reducido de pacientes puede debutar con un SHU sin haber presentado el cuadro previo de diarrea.

Hallazgos de laboratorio. En el hemograma se observan elementos de anemia hemolítica microangiopática (hematocrito $<30 \%$, con eritrocitos fragmentados o esquistocitos, reticulocitosis), trombocitopenia

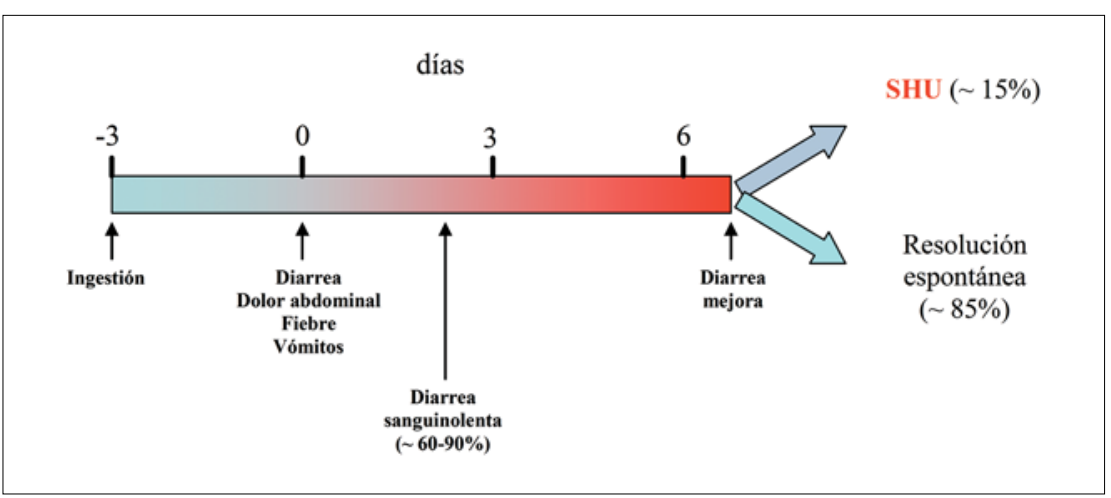

Figura 2. Evolución cronológica de la infección por Escherichia coli productora de shigatoxina.

(plaquetas $<150.000 \mathrm{x} \mathrm{mm}^{3}$ ) y leucocitosis. En relación a la anemia puede observarse niveles elevados de LDH y bilirrubinemia y disminuidos de haptoglobina, con test de Coombs negativo.

Los reactantes de fase aguda, como PCR y VHS, suelen estar elevados.

Pruebas de coagulación, como tiempo de protrombina y TTPK, se encuentran normales y los productos de degradación del fibrinógeno están elevados.

La creatininemia y el nitrógeno ureico pueden elevarse, en forma variable. Los electrolitos plasmáticos usualmente muestran hiponatremia e hiperkalemia.

Al examen de orina pueden observarse elementos característicos de un síndrome nefrítico, es decir, proteinuria, hematuria y cilindruria ${ }^{24}$.

\section{Manejo clínico del síndrome hemolítico urémico}

No existe, actualmente, un tratamiento específico para el SHU, la prevención sigue siendo la medida más importante y de mayor costo-beneficio.

Para aquellos casos en que el cuadro clínico es sugerente, se recomienda la hospitalización con medidas de aislamiento entérico y medición frecuente de parámetros básicos como peso diario, balance hídrico y diuresis. Debe tenerse presente que un ascenso de peso no necesariamente traduce una sobrecarga intravascular en las primeras etapas de la enfermedad, ya que puede ocurrir edema secundario a hipoalbuminemia y "leak" capilar.

Es importante asegurar una buena vía venosa (idealmente central) para el aporte de volumen adecuado, transfusiones y, eventualmente, alimentación parenteral $^{9}$. 
Recientemente, Ake y cols, recomendaron rehidratación y mantención intravenosa con cristaloides isotónicos para obtener una óptima protección del riñón. En este estudio, aquellos pacientes cursando cuadros disentéricos por STEC y que recibieron esta expansión de volumen parenteral, desarrollaron un SHU con menor compromiso renal, y por ende, sin requerimientos de diálisis ${ }^{24}$.

Si el paciente está oligúrico y con evidencias de hipervolemia (edema, hipertensión arterial y venosa, signos de sobrecarga cardíaca), se debiera iniciar la administración de furosemida en bolos de 1-2 mg/ $\mathrm{kg}$, eventualmente, continuar con infusión i.v, continua de 0,1 a $0,3 \mathrm{mg} / \mathrm{kg} / \mathrm{hr}$. Si no hay respuesta diurética, la furosemida debiera suspenderse e iniciar una terapia de reemplazo renal agudo, usualmente diálisis peritoneal.

De los pacientes diagnosticados con SHU, aproximadamente 30 a $40 \%$ requerirá de alguna técnica de diálisis, especialmente relacionada a hipervolemias refractarias a diuréticos, alteraciones electrolíticas y/o ácido-básicas intensas, síndrome urémico o necesidad de "espacio" intravascular para transfusiones, fárma$\cos \mathrm{y}$ nutrientes.

Las transfusiones de eritrocitos deben indicarse con hemoglobina < a $7 \mathrm{gr} / 1$, o antes si hay compromiso cardio-respiratorio que lo requiera. Debido al riesgo futuro de insuficiencia renal crónica y transplante renal, los eritrocitos debieran ser irradiados y filtrados. No se deben transfundir plaquetas a menos que haya sangrado activo, trombocitopenia $<20.000 / \mathrm{mm}^{3}$ con riesgo hemorrágico alto o se requiera realizar algún procedimiento invasor.

Pronóstico. Con el advenimiento de modernas unidades de cuidados intensivos y técnicas dialíticas pediátricas, la mortalidad del SHU ha descendido desde 30 a $50 \%$ hasta $\sim 3$ a $5 \%$ en las últimas tres décadas. El riesgo de progresar a daño renal crónico terminal es de $\sim 10 \%$, si bien un porcentaje bastante mayor puede quedar con grados variables de daño renal subclínico. La oligoanuria prolongada (mayor a 2 semanas) en el cuadro agudo se relaciona con peor pronóstico renal. La presencia de pródromo diarreico y la evidencia de infección intestinal por STEC se asocian independientemente a un mejor pronóstico renal $^{25}$. En un estudio de Oakes y cols, en pacientes fallecidos con SHU D+ se observó que el compromiso grave del SNC fue la principal causa de muerte, seguido de las complicaciones gastrointestinales. En este estudio, los principales predictores de mortalidad fueron la oligoanuria, deshidratación, leucocitosis $>20.000 / \mathrm{mm}^{3}$ y el hematocrito $>23 \%$, al momento del diagnóstico ${ }^{26}$.
Nuevas estrategias terapeúticas para el tratamiento de las infecciones por Escherichia coli productora de shigatoxina y del síndrome hemolítico urémico

Existe cierto grado de acuerdo, aunque no un consenso total, que el uso de antimicrobianos no está recomendado en la fase de diarrea inicial ni en el SHU, ya que no se han observado beneficios claros y existen algunas evidencias que indican que los antimicrobianos podrían constituir un factor de riesgo para el desarrollo de $\mathrm{SHU}^{27,28}$.

Basados en el antecedente que el daño en el SHU es producido por la Stx, se han orientado los esfuerzos hacia el desarrollo de agentes que se unan a las Stxs y bloqueen su acción a nivel de las células eucarióticas, lo que resumimos a continuación:

- Se han sintetizado varias moléculas análogas del receptor Gb3, entre ellas el Synsorb-Pk, que fue evaluado en un ensayo clínico bien diseñado que incluyó 150 niños con SHU. La administración oral de esta molécula no mostró eficacia en disminuir la letalidad, ni la necesidad de diálisis o trasfusiones en los pacientes, por lo que esta línea fue abandonada. La conclusión de este estudio fue que es muy tarde intentar bloquear la toxina en la etapa de SHU, ya que se encuentra fijada a los receptores ${ }^{29}$.

Se han desarrollado otras moléculas con mayor afinidad por el receptor Gb3, las cuales han mostrado proteger a ratas de una dosis letal de STEC O157 y que deberían ser evaluadas en ensayos clínicos en pacientes durante la etapa precoz de la infección o, idealmente, ser utilizadas en los $\operatorname{contactos}^{30}$ en situación de brotes.

- Otro enfoque ha sido utilizar la ingeniería genética para crear bacterias recombinantes, en este caso una cepa de $E$. coli no patogénica, que exprese en el lipolisacárido de su pared el trisacárido correspondiente al receptor Gb3. Estudios en animales han mostrado que esta bacteria es efectiva en fijar las toxinas Stx1 y Stx2 y proteger a ratas de una dosis letal con STEC O15731.

- Un camino en el cual se ha adelantado bastante, es el desarrollo de anticuerpos monoclonales humanizados contra las Stxs. En estudios preclínicos, estos anticuerpos administrados por vía intraperitoneal protegieron a cerdos infectados 6-12 horas previas con $\mathrm{STEC}^{32,33}$. Estos anticuerpos han superado con éxito las pruebas de toxicidad en ratas. Ya se ha iniciado la evaluación en seres humanos y se han realizado estudios de Fase I para evaluar seguridad. La próxima etapa serán los estudios de eficacia clínica. 


\section{Seguimiento a largo plazo}

Debido al riesgo de desarrollar una enfermedad renal crónica futura, los pacientes que han tenido un SHU deben ser seguidos por años. Aquellos niños que evidencian proteinuria persistente o hipertensión arterial dentro de los dos primeros años de seguimiento tienen un riesgo mayor de presentar esta complicación renal ${ }^{25}$. Además de controlar su presión arterial, estos pacientes deben ser controlados con examen de orina buscando proteinuria (idealmente microalbuminuria por ser más sensible), ecografía renal para observar ecogenicidad cortical y crecimiento renal y, eventualmente, pruebas de función renal, como depuración de creatinina.

\section{Prevención de las infecciones por Escherichia coli productora de shigatoxina}

Conociendo las fuentes de infección, fundamentalmente productos cárneos de origen bovino o porcino, la recomendación es consumirlos bien cocidos. En el hogar es importante no mezclar carne cruda con verduras $\mathrm{u}$ otros alimentos que se consumirán sin cocer. Especial énfasis se debe dar a la limpieza de las superficies y utensilios en la cocina, para evitar la contaminación cruzada.

Es necesario además tener precauciones con el contacto con animales en las granjas.

La industria alimentaria debe incorporar en los controles de calidad, la detección de STEC en productos cárneos y esto debería ser una exigencia de las autoridades regulatorias en esa área.

Vacunas. Tratándose de una zoonosis, una estrategia racional sería intentar eliminar el reservorio animal, aunque considerando que las STEC forman parte de la microbiota comensal de animales, erradicarlas puede ser tarea difícil.

Se han desarrollado vacunas para bovinos en base a las proteínas secretadas de la isla de patogenicidad de los STEC. Esta vacuna administrada por vía parenteral a terneros mostró una disminución desde 23 a 9\% en la excreción de $\mathrm{STEC}^{34}$.

Otra estrategia ha sido el desarrollo de vacunas en base a la proteína intimina (involucrada en la adherencia al epitelio intestinal). Un ensayo en cerdos lechones con este tipo de vacuna mostró disminución de la colonización por STEC de 83 a $23 \%$ y también se observó un impacto significativo en la patología gastrointestinal ${ }^{35}$.

En vacunas para uso en humanos, se ha explorado una vacuna contra infección por O157 basada en la fracción polisacárida del lipopolisacárido de $\mathrm{O} 157$, conjugada a exotoxina purificada de Pseudomonas aeruginosa, la cual ha mostrado una potente respuesta de anticuerpos en voluntarios ${ }^{36}$.

El acceso a vacunas todavía está lejano, por lo cual es necesario reforzar las medidas de prevención en el manejo de los alimentos en el hogar.

\section{Resumen}

Se revisan y actualizan aspectos clínicos y epidemiológicos de las infecciones por Escherichia coli productora de shigatoxina (STEC), y el síndrome hemolítico urémico (SHU). Se incluyen resultados de una vigilancia de SHU en 14 centros centinelas (20002002), que mostró una incidencia promedio de 3,4 casos por 100.000 niños, $78 \%$ en el grupo de 6 a 48 meses. Esta vigilancia reflejó una situación endémica, con aumento en verano. Se analiza la observación clínica protocolizada de 119 pacientes con SHU hospitalizados en la Región Metropolitana (RM) (1988 y 2002). Edad promedio: 16 meses. El 578\% tenía diarrea con sangre, $9 \%$ no tenía diarrea previa, $60 \%$ recibió antibacterianos, $72 \%$ presentó oligoanuria y $53 \%$ necesitó diálisis. El 31\% tuvo compromiso de conciencia y $15 \%$ presentó convulsiones. Letalidad 3\%. Se analizan brotes de STEC asociados a alimentos ocurridos en la RM en el hogar (2), un jardín infantil (1) y en un servicio de neonatología (1). Finalmente, se entregar recomendaciones para el manejo clínico y prevención, se revisan los criterios diagnósticos, nuevas estrategias terapéuticas y progresos en el desarrollo de vacunas.

\section{Referencias}

1.- Neill M, Tarr P, Clausen C, Christie D, Hickman R. Escherichia coli $0157:$ H7 as the predominant pathogen associated with the hemolytic uremic syndrome: a prospective study in the Pacific Northwest. Pediatrics 1987; 80: 37-40.

2.- Rowe P, Orrbine E, Wells G, McLaine P. Epidemiology of hemolytic-uremic syndrome in Canadian children from 1986 to 1988 . J Pediatrics $1991 ; 119$ : 218-24.

3.- López E L, Díaz M, Devoto S, Grinstein S, Woloj M, Murray M, et al. Evidence of infection with organisms producing Shigalike toxin in household contacts of children with the hemolytic uremic syndrome. Pediatrics Infect Dis J 1991; 10:20-4.

4.- Prado V, Martínez J, Arellano C, Levine M.
Variación temporal de genotipos y serogrupos de E. coli enterohemorrágicos aislados en niños chilenos con infecciones intestinales o síndrome hemolítico-urémico. Rev Méd Chile 1997; 125: 291-297.

5. - Michino H, Araki K, Minami S, Takaya S, Sakai N, Miyazaki M, et. al. Massive outbreak of Escherichia coli O157:H7 infection in schoolchidren in Sakai city, Japan, associated with consumption of white 
radish sprouts. Am J Epidemiol 1999; 150: 787-96.

6.- Gasser C, Gautier E, Steck A, Siebermann R E, Oechslin R. Hämolytisch-urämische: bilaterale nierenindennekrosen bei akuten erworbenen hämolytischen anämien. Schweiz Med Wochenschr 1955; 85: 905-9.

7.- Karmali M, Petric M, Lim C, Fleming P, Arbus G, Lior H. The association between idiopathic hemolytic uremic syndrome and infection by verotoxin-producing Escherichia coli. J Infect Dis 1985; 151: 775-82

8.- Nataro J P, Kaper J B. Diarrheagenic Escherichia coli. Clin Microbiol Rev 1998; 11: 142-201.

9.- Tarr P, Gordon C, Chandler W. Shiga-toxin producing Escherichia coli and haemolytic uraemic syndrome. Lancet 2005; 365: 1073 86.

10. - Prado V, Cordero J, Garreaud de M C, Olguín H, Arellano C, Nachar C L, et al. Escherichia coli enterohemorrágico, principal responsable del síndrome hemolítico urémico en niños chilenos. Evaluación de diferentes técnicas de diagnóstico. Rev Méd Chile 1995; 123: 13-22.

11.- Vizcaya M C, Sandoval C, Salín M P, Prado V. Impacto del síndrome hemolítico urémico en las distintas áreas de salud de la Región Metropolitana. Rev Chil Infect 1996; 13: 223-30.

12.- Vidal M, Kruger E, Durán C, Lagos R, Levine M, Prado V, et al. Single multiplex PCR assay to identify simultaneously the six categories of diarrheagenic Escherichia coli associated with enteric infections. J Clin Microbiol 2005; 43: 5362-5.

13. - Martin D L, MacDonald K L, White K E, Soler J T, Osterholm M T. The epidemiology and clinical aspects of the hemolytic uremic syndrome in Minnesota. N England J Med 1990; 323: 1161-7.

14.- Rivas E, Miliwebsky E, Chinen I, Deza N, Leotta G. Epidemiología del síndrome hemolítico urémico en Argentina. Diagnóstico del agente etiológico, reservorios y vías de transmisión. Medicina 2006; 66: 27-32.

15.- Zambrano P, Delucchi A, Hevia P, Nazal V, Rosati P, Barrera P. Síndrome hemolítico urémico en Santiago de Chile: Evolución de la función renal y factores pronósticos. Rev Chil Pediatr 2005; 76: 48-56.

16.- Swerdlow D L, Sparling P H, Griffin P M. Importance of outbreak investigating in defining the epidemiology of Escherichia coli $\mathrm{O} 157: \mathrm{H} 7$ infections in the United States, In Michino H, Araki K, Minami S, Takaya S, Sakai N, Miyazaki M, et al. Massive outbreak of Escherichia coli O157:H7 infection in schoolchidren in Sakai city, Japan, associated with consumption of white radish sprouts. Am J Epidemiol 1999; 150: 787-96.

17. - Centers for Disease Control and Prevention. Ongoing multistate outbreak of Escherichia coli serotype O157:H7 infections associated with consumption of fresh spinach-United States, September 2006. MMWR Morb Mortal Wkly Rep 2006; 55: 1045-6.

18. - San Martín M, Araya P, Olivares B, Hormazábal J C, Beltrán C, Morales R, et al. XXIII Congreso Chileno de Infectología y VI Encuentro de Infectólogos del Cono Sur, Viña del Mar, 8-10 noviembre 2006, CO-08, pág 37.

19.- Borie C, Monreal Z, Guerrero P, Sánchez M L, Martínez J, Arellano C, et al. Prevalence and characterization of enterohemorrhagic Escherichia coli isolated from healthy cattle and pigs slaughtered in Santiago, Chile. Arch Med Vet 1997; 29: 205-12.

20.- Griffin P, Tauxe R. The epidemiology of infection caused by Escherichia coli O157:H 7, other enterohemorrhagic E. coli, and the associated hemolytic uremic syndrome. Epid Reviews 1991; 13: 60-98

21.- Proulx F, Seidman E G, Karpman D. Pathogenesis of Shigatoxin-associated hemolytic uremic syndrome. Pediatrics Research 2001; 50: 163-71

22.- Teel L D, Daly J A, Jerris R C, Maul D, Svanas G, O'Brien A, et al. Rapid detection of Shiga-toxin producing Escherichia coli by optical immunoassay. J Clin Microbiol 2007; 45: $3377-80$.

23.- Cavagnaro F, Gana J, Lagomarsino E, Vogel S, Gederlini A. Síndrome hemolítico urémico. Experiencia de un centro pediátrico. Rev Méd Chile 2005; 133: 781-7.

24.- Ake J, Jelacic S, Ciol M, Watkins S, Murray K, Christie D, et al. Relative nephroprotection during Escherichia coli O157:H7 infections: Association with intravenous volume expansion. Pediatrics 2005; 115: 673-80.

25.- Gianviti A, Tozzí A, De Petris L, Caprioli A, Ravá L, Edefonti A, et al. Risk factors for poor renal prognosis in children with hemolytic uremic syndrome. Pediatr Nephrol 2003; 18: 1229-35.

26.- Oakes R, Siegler R, McReynolds M,
Pysher T, Pavia A. Predictors of fatality in postdiarrheal hemolytic uremic syndrome. Pediatrics 2006; 117: 1656-62.

27.- Saldar N, Adnan S, Gangnon R E, Maki D G. Risk of hemolytic uremic syndrome after antibiotic treatment of Escherichia coli O157:H7 enteritis. JAMA 2002; 288: 9961001

28.- Wong C S, Jelacic S, Habeeb R L, Watkins S L, Tarr P L. The risk of the hemolyticuremic syndrome after antibiotic treatment of Escherichia coli $0157: \mathrm{H} 7$ infections. N Engl J Med 2000; 342: 1930-6.

29. - Trachtman H, Cnaan A, Christen E, Gibbs K, Zhao S, Acheson D W, et al. Effect of an oral shiga toxin-binding agent on diarrhea-associated haemolytic uremic syndrome in children. JAMA 2003; 290: 1337-44.

30.- Watanabe M, Matsuoka K, Kita E, Igai K, Higashi N, Miyagawa A, et al. Oral therapeutic agents with highly clustered globotriose for treatment of shiga toxigenic Escherichia coli infections. J Infect Dis 2004; 189: 360-8.

31.- Pinyon R A, Paton J C, Paton A W, Botten J A, Morona R. Refinement of a therapeutic shigatoxin-binding probiotic for human trials. J Infect Dis 2004; 189 : 1547-55

32.- Mukherjee J, Chios K, Fishwild D, Hudson D, O'Donnell S, Rich S M, et al. Production of and characterization of protective human antibodies against shiga toxin 1 . Infect Immun 2002; 70: 5896-9.

33.- Mukherjee J, Chios K, Fishwild D, Hudson D, O'Donnell S, Rich S M, et al. Human Stx2specfic monoclonal antibodies prevent systemic complications of Escherichia coli O157:H7 infection. Infect Immun 2002; 70: 612-9.

34.- Potter A A, Klashinsky S, Li Y, Frey E, Towsend H, Rogan D, et al. Decreased shedding of Escherichia coli O157:H7 by cattle following vaccination with type III secreted proteins. Vaccine 2004; 22: 362-9.

35.- Dean-Nystrom E A, Gansherof L J, Mills M, Moon H W, Alison D. O’Brien Vaccination of pregnant dams with intimino 157 protects suckling piglets from Escherichia coli O157:H7 infection. Infect Immun 2002; 70: 2414-8.

36.- Ahmed A, Li J, Shiloach Y, Robbins J B, Szu S C. Safety and immunogenicity of Escherichia coli O157 O-specific polysaccharide conjugate vaccine in $2-5$ year-old children. J Infect Dis 2006; 193: 512-21. 